\title{
Identification and Biological Characterization of Leishmania (Viannia) guyanensis Isolated from a Patient with Tegumentary Leishmaniasis in Goiás, a Nonendemic Area for This Species in Brazil
}

\author{
Alause da Silva Pires, ${ }^{1}$ Arissa Felipe Borges, ${ }^{1}$ Adriano Cappellazzo Coelho, ${ }^{2}$ \\ Miriam Leandro Dorta, ${ }^{1}$ Ruy de Souza Lino Junior, ${ }^{1}$ Ledice Inacia de Araújo Pereira, ${ }^{1}$ \\ Sebastião Alves Pinto, ${ }^{3}$ Milton Adriano Pelli de Oliveira, ${ }^{1}$ \\ Grazzielle Guimarães de Matos, ${ }^{1}$ Ises A. Abrahamsohn, ${ }^{4}$ Silvia Reni B. Uliana, ${ }^{2}$ \\ Glória Maria Collet de Araújo Lima, ${ }^{4}$ and Fátima Ribeiro-Dias ${ }^{1}$ \\ ${ }^{1}$ Instituto de Patologia Tropical e Saúde Pública, Universidade Federal de Goiás, Rua 235 S/N, Setor Universitário, \\ 74605-050 Goiânia, GO, Brazil \\ ${ }^{2}$ Instituto de Ciências Biomédicas, Universidade de São Paulo, SP, Brazil \\ ${ }^{3}$ Instituto Goiano de Oncologia e Hematologia e Faculdade de Medicina, Universidade Federal de Goiás, GO, Brazil \\ ${ }^{4}$ Universidade de São Paulo, SP, Brazil
}

Correspondence should be addressed to Fátima Ribeiro-Dias; fatimardias@gmail.com

Received 5 June 2015; Accepted 4 August 2015

Academic Editor: Lidia Chomicz

Copyright (C) 2015 Alause da Silva Pires et al. This is an open access article distributed under the Creative Commons Attribution License, which permits unrestricted use, distribution, and reproduction in any medium, provided the original work is properly cited.

\begin{abstract}
The aim of this study was to characterize clinical field isolates of Leishmania spp. obtained from patients with American Tegumentary Leishmaniasis (ATL) who live in Goiás state, Brazil. The presumed areas of infection were in Goiás, Tocantins, and Pará states. Three isolates of parasites were identified as L. (Viannia) braziliensis and one as L. (V.) guyanensis. The in vitro growth profiles were found to be similar for all parasites. Nevertheless, in C57BL/6 mice, L. (V.) guyanensis infection was better controlled than L. (V.) braziliensis. Yet in C57BL/6 mice deficient in interferon gamma, L. (V.) guyanensis lesions developed faster than those caused by L. (V.) braziliensis isolates. In BALB/c mice, the development of lesions was similar for isolates from both species; however, on the 11th week of infection, amastigotes could not be observed in macrophages from L. (V.) guyanensis-infected mice. Thus, $L$. (V.) guyanensis can be circulating in Goiás, a state where autochthonous cases of this species had not yet been reported. Considering the difficulties to differentiate L. (V.) guyanensis from L. (V.) braziliensis at the molecular, morphological, and clinical (human and murine models) levels, the presence of $L$. (V.) guyanensis infections is possibly underestimated in several regions of Brazil.
\end{abstract}

\section{Introduction}

Leishmaniases are protozoan diseases caused by more than 20 Leishmania species, which are transmitted by about 30 species of phlebotomine sand flies. Human infections cause three strikingly different clinical presentations and numerous clinical varieties ranging from asymptomatic to disfiguring forms of tegumentary and potentially fatal visceral leishmaniasis. American Tegumentary Leishmaniasis (ATL) presents a spectrum of clinical manifestations characterized by cutaneous (CL), mucosal (ML), disseminated (DL), and diffuse cutaneous leishmaniasis (DCL) [1,2]. Brazil together with other nine countries accounts for $70-75 \%$ of estimated CL cases in the world [3]. A report of the Brazilian Secretary's Office of Surveillance in Health showed a geographic expansion of ATL during the 1980s from the Northern 
towards the Southern region, and, in 2003, all Brazilian states registered autochthonous cases [4]. In 2013, the distribution per Brazilian region was reported as follows: Northern region with 8,407 new cases (49.5 cases per 100.000 population); Central Western region with the second highest prevalence, 2,922 new cases (19.5 cases per 100.000 population), Northeastern region with 5,355 new cases (9.6 cases per 100.000 population), Southeastern region with 1,150 new cases (1.4 cases per 100.000 population), and Southern region with 296 new cases (1.0 case per 100.000 population) [5, 6].

Three main Leishmania species are responsible for ATL in Brazil: L. (Viannia) braziliensis, L. (Leishmania) amazonensis, and L. (Viannia) guyanensis. Besides, L. (Viannia) lainsoni, L. (Viannia) naiffi, and L. (Viannia) shawi have also been identified as new agents of ATL in the Northern region. The species L. (V.) braziliensis presents wider geographic distribution than the other species in Brazil (it is reported in all Brazilian states) whereas L. (V.) guyanensis is believed to be restricted to the Northern region $[7,8]$. The distribution of Leishmania species depends on the vectors, animal reservoirs, and hosts as well as the ecology of the endemic areas. As L. (V.) braziliensis is widely distributed in South America, this species may be transmitted by several different sand flies species and different animal species can be the reservoirs in distinct ecologic and geographical areas, which increases the molecular diversity of the parasites $[9,10]$. In Brazil, L. (V.) braziliensis is commonly transmitted by Lutzomyia whitmani (Northeastern, Central Western, and Southeastern regions), L. wellcomei (Northern region), L. intermedia (Southeastern region), and L. neivai (Southern region). Besides, L. umbratilis has also been suggested as vector for L. (V.) braziliensis in Mato Grosso state (Central Western region). The latter species is the main vector for $L$. (V.) guyanensis, which is also transmitted by L. anduzei and $L$. whitmani $[1,9,11,12]$. In Goiás state (Central Western region), L. intermedia and L. whitmani have been associated with ATL $[13,14]$. Mammal reservoirs of $L$. (V.) braziliensis can be found among numerous species of forest animals, especially rodents, whereas L. (V.) guyanensis is more frequent in sloths, anteaters, and opossums [8].

L. (V.) braziliensis and L. (V.) guyanensis are associated with the same clinical manifestations of ATL as localized cutaneous, disseminated, and mucosal leishmaniasis can be ascribed to both species [15-18]. Therefore, determining the Leishmania species causing disease in a patient cannot rely on clinical criteria and parasite identification is essential to prescribe the best species-specific therapeutic regimen [15, 17]. Furthermore, genetic heterogeneity and clonal diversity, which leads to variability in parasite virulence, are also common among L. (Viannia) spp. parasites $[10,19,20]$.

In the present study, we characterized four Leishmania spp. isolates obtained from patients with ATL assisted at the Tropical Disease Hospital of Goiânia, Goiás, Brazil, a reference center for leishmaniasis diagnosis and treatment in Goiás state (Central Western region). The leishmaniasis cases from Northern and Central Western Brazil are referred to this hospital. The patients in our study were probably infected in Goiás (Central Western region), Tocantins, or Pará (Northern region) states. A comprehensive knowledge of the species and the characteristics of the parasites are very important for controlling the disease, mainly when patients migrate to other regions/states with different ecosystems and increase the threat of new Leishmania foci.

\section{Materials and Methods}

2.1. Mice. Female C57BL/6 (wild-type [WT]) or C57BL/6 IFNgamma knockout (IFN $\gamma \mathrm{KO} \mathrm{C} 57 \mathrm{BL} / 6)$ and $\mathrm{BALB} / \mathrm{c}$ mice, six to eight weeks old, were obtained from the breeding animal facilities of the IPTSP/Federal University of Goiás, Goiânia, Brazil. All the animal handling and procedures were approved by the Ethical Committee from Clinical Hospital of the Federal University of Goiás on the ethical handling of research animals.

2.2. Patients. Four patients were assisted at the Tropical Disease Hospital (Anuar Auad, Goiânia, Goiás, Brazil) with the diagnostic hypothesis of leishmaniasis. All of them live in Goiás, but the presumed areas of infection were Goiás, Tocantins, and Pará/Maranhão border. Diagnosis of ATL was confirmed by epidemiological, clinical, and laboratory analyses. The patients' data are presented in Table 1. The protocols on this investigation relative to human patients and animals were approved by the Ethical Committee from Hospital das Clínicas, Universidade Federal de Goiás, and all patients signed an informed consent form.

2.3. Parasite Isolation and Cultures. A fragment of the cutaneous lesion biopsy was macerated and inoculated in mice footpads (IFN $\gamma \mathrm{KO} \mathrm{C57BL/6)}$ ) or directly cultured at $26^{\circ} \mathrm{C}$ in Grace's Insect Cell Culture Medium (Gibco-BRL Life Technologies, Grand Island, NY, USA) containing 20\% heatinactivated fetal bovine serum (Cripion, Andradina, SP, Brazil), $2 \mathrm{mM}$ glutamine, penicillin $(100 \mathrm{U} / \mathrm{mL})$, and streptomycin $(100 \mu \mathrm{g} / \mathrm{mL})$ (supplements and antibiotics were purchased from Sigma Chemical Co., St. Louis, MO, USA). After 1-2 months draining lymph nodes from the animals were processed as described [21] and cultured in complete Grace's medium. After being expanded in culture, the parasite isolates were cryopreserved in liquid nitrogen. The parasite isolates were thawed and expanded once in complete Grace's medium before use in all experiments. All these procedures were previously described [21]. The parasite isolates were coded as WWS5 (MHOM/BR/2005/WSS5), UAF5 (MHOM/ BR/2005/UAF5), HPV6 (MHOM/BR/2006/HPV6), and PLR6 (MHOM/BR/2006/PLR6). The isolates WWS5, UAF5, and HPV6 were previously identified as L. (V.) braziliensis [22, 23].

2.4. Molecular Characterization: Polymerase Chain Reactions (PCR). The identification of the isolates was based on three strategies: (1) small subunit ribosomal RNA (SSU rDNA) was sequenced as previously described, using primers S12/S4 [24]. Positive control reactions were performed using a reference genomic DNA purified from axenic cultures of $L$. (L.) amazonensis MHOM/BR/1973/M2269, L. (V.) braziliensis MHOM/BR/1975/M2903, L. (L.) chagasi MHOM/BR/1972/ LD, L. (V.) guyanensis MHOM/BR/75/M4147, or L. (V.) shawi 
TABLE 1: ATL patients from whom the isolates were obtained ${ }^{\mathrm{a}}$.

\begin{tabular}{|c|c|c|c|c|}
\hline Patients & HPV & UAF & WSS & PLR \\
\hline $\operatorname{Sex}^{\mathrm{b}}$ & M & M & M & $\mathrm{M}$ \\
\hline $\mathrm{Age}^{\mathrm{c}}$ & 46 & 29 & 22 & 19 \\
\hline Clinical form ${ }^{\mathrm{d}}$ & $\mathrm{CL}$ & $\mathrm{CL}$ & $\mathrm{CL}$ & $\mathrm{CL}$ \\
\hline Number of lesions & 2 & 1 & 1 & 3 \\
\hline Type of lesions & Ulcerated & Ulcerated & Ulcerated & Ulcerated \\
\hline Time of lesion ${ }^{\mathrm{e}}$ & $3 \mathrm{~m}$ & $2 \mathrm{~m}$ & $8 \mathrm{~m}$ & $2 \mathrm{~m}$ \\
\hline Lesion site & Upper limbs & Lower limb & Lower limb & Lower limbs \\
\hline Satellite adenomegaly & $\begin{array}{c}\text { No } \\
\text { (lymphangitis) }\end{array}$ & No & No & No \\
\hline Leishmanin skin test & No reaction & $5 \mathrm{~mm}$ & $N^{f}$ & $5 \mathrm{~mm}$ \\
\hline Histopathological analysis & Presence of amastigotes & Presence of amastigotes & NR & $\begin{array}{l}\text { Presence of } \\
\text { amastigotes }\end{array}$ \\
\hline Treatment & Pentavalent antimonial & $\begin{array}{l}\text { Pentavalent antimonial } \\
\text { (two cycles) }\end{array}$ & No treatment & $\begin{array}{l}\text { Pentavalent } \\
\text { antimonial }\end{array}$ \\
\hline Indirect immunofluorescence reaction & No reaction & $\begin{array}{c}\text { No reaction } \\
80 \text { (after treatment) }\end{array}$ & NR & 160 \\
\hline Clinical outcome & Clinical cure & Clinical cure & No treatment & NR \\
\hline Presumed place of infection & $\begin{array}{l}\text { Tocantins } \\
(\mathrm{TO})^{\mathrm{g}}\end{array}$ & $\begin{array}{l}\text { Tocantins } \\
\text { (TO) }\end{array}$ & $\begin{array}{l}\text { Goiás } \\
(\mathrm{GO})^{\mathrm{h}}\end{array}$ & $\begin{array}{c}\text { Pará }{ }^{\mathrm{i}} / \text { Maranhão } \\
(\mathrm{MA})^{j} \\
\text { (PA) }\end{array}$ \\
\hline
\end{tabular}

a Patients were assisted at Anuar Auad Tropical Disease Hospital, Goiânia, Goiás (2005-2006).

${ }^{b} \mathrm{~F}=$ feminine, $\mathrm{M}=$ masculine, ${ }^{\mathrm{c}}$ age in years, ${ }^{\mathrm{d}}$ clinical form $\mathrm{CL}=$ cutaneous localized, ${ }^{\mathrm{e}}$ time of lesion $=$ in months, and ${ }^{\mathrm{f}} \mathrm{NR}=$ patient did not return. ${ }^{\mathrm{g}}$ Tocantins (TO) is a state of the Northern region, ${ }^{\mathrm{h}}$ Goiás (GO) is a state in Central Western region, ${ }^{\mathrm{i}}$ Pará (PA) is a state of the Northern region, and ${ }^{\mathrm{j}}$ Maranhão (MA) is a state of the Northeastern region (border with Pará).

$\mathrm{MCEB} / \mathrm{BR} / 84 / \mathrm{M} 8408$, while in negative controls no genomic DNA was added. The amplified product was analyzed in a $2 \%$ agarose gel electrophoresis stained with ethidium bromide. The nucleotide sequence of the $520 \mathrm{bp}$ fragment was obtained directly by automatic sequencing using an ABI Big-Dye kit as described [23]. (2) Sets of primers were used in PCR assays to discriminate L. (V.) braziliensis (G6PDISVC and G6PD-ISVB) from other organisms of the Viannia subgenus (G6PD-ISVG and G6PD-LVF) as described before [25]. PCR reactions were prepared in $50 \mu \mathrm{L}$ final volume containing $50 \mathrm{mM} \mathrm{KCl}, 1.5 \mathrm{mM} \mathrm{MgCl}_{2}, 10 \mathrm{mM}$ Tris- $\mathrm{HCl}$ (pH 8.3 ), $0.2 \mathrm{mM}$ of each deoxyribonucleotide, $15 \mathrm{pmol}$ of each primer, $2.5 \mathrm{U}$ of Taq DNA polymerase (Gibco), and $100 \mathrm{ng}$ of template DNA. (3) The ribosomal internal transcribed spacer (ITS) was amplified using primers IR1 and IR2 [26]. The approximately $1 \mathrm{~kb}$ PCR amplified product was digested with Hae III as described [27] and analysed by gel electrophoresis. The amplified product was also purified from agarose gels using the QIAquick PCR purification kit (Qiagen, Valencia, USA) and cloned in pGEM-T easy (Promega Corporation, Madison, WI, USA). The nucleotide sequence of three independent positive clones, confirmed previously by restriction analysis, was determined as described above using pUC/M13, IR1, IR2, 5.8F (5' GCAGTAAAGTGCGATAAGTGG $3^{\prime}$ ), and 5.8R ( $5^{\prime}$ GGAAGCCAAGTCATCCATC $\left.3^{\prime}\right)$ primers. Nucleotide sequence analyses were performed using Lasergene Software (DNASTAR) and Clone Manager 9.0 Software. Phylogenetic analysis was performed using RAxML [28].
2.5. In Vitro Growth of Leishmania Isolates. The parasite isolates extracted from draining lymph nodes of infected IFN $\gamma$ $\mathrm{KO}$ C57BL/6 mice were cultured at an initial concentration of $5 \times 10^{5} / \mathrm{mL}$ in 24 -well culture plates (TPP, Techno Plastic Products, Trasadingen, Swizerland) in complete Grace's medium at $26^{\circ} \mathrm{C}$. Samples of parasites were counted daily for 13 days in a hemocytometer after dilution in $2 \%$ formaldehyde solution in PBS, under light microscopy.

2.6. Infection of Mice. Groups of four mice were injected subcutaneously (s.c.) with $5 \times 10^{6}$ live promastigotes $(50 \mu \mathrm{L})$ in stationary phase of growth into the left hind footpad. Lesion development was followed by measuring the thickness of the infected paw with a dial caliper at weekly intervals and expressed by the arithmetic mean and standard error mean (SEM) of the net thickness increase (infected minus control contralateral paw thickness). Following ethical procedures, when the paw lesion reached $5 \mathrm{~mm}$ in thickness or presented ulceration, the mice were euthanized.

2.7. Tissue Processing for Optical Microscopy. To analyze the local inflammatory reaction and presence or absence of parasites, footpads were removed postmortem on the 5th or 6th (IFN $\gamma$ KO C57BL/6) or 11th (C57BL/6 WT, BALB/c) week after infection, excised, and prefixed with $10 \%$ formalin, followed by fixation in Bouin solution (picric acid $75 \%$, glacial acetic acid 5\%, and formaldehyde $10 \%$ ) prior to paraffin embedding. Five $\mu \mathrm{m}$ sections from the material were stained 
with hematoxylin and eosin $(\mathrm{H} \& \mathrm{E})$ and examined under light microscopy.

2.8. Statistical Analysis. Data are presented as mean \pm standard error of the mean (SEM). Two way ANOVA/Bonferroni was used to compare the data, and the differences were considered significant when $P<0.05$.

\section{Results}

3.1. Patient Profiles. The age of patients varied from 19 to 46 years and they had one to three cutaneous lesions located in the limbs that appeared from two to eight months before the diagnosis. All patients were diagnosed with ATL, presenting the cutaneous localized clinical form (LCL) according to clinical and laboratory analyses. In all patients, the lesions were ulcerated. Patients' data are presented in Table 1.

3.2. Molecular Characterization of Leishmania Isolates. SSU rDNA amplification was performed on four clinical field isolates and controls, using primers S12/S4 and the PCR products were analyzed by automatic sequencing. The nucleotide sequence of the four isolates identified HPV6, UAF5, WSS5, and PLR6 as species of the Viannia subgenus (data not shown). All samples were also analyzed by PCR of the G6PD gene with primers specific for L. (V.) braziliensis or "nonbraziliensis" Viannia species. This analysis confirmed the identity of HPV6, UAF5, and WSS5 as L. (V.) braziliensis and of PLR6 as a "non-braziliensis" isolate (data not shown).

The identification of the PLR6 isolate was based on the analysis of ribosomal ITSs 1 and 2 . Approximately $1 \mathrm{~kb}$ fragment was amplified and digested with Hae III. The analysis of restriction fragment polymorphisms indicated that PLR6 displayed a pattern compatible with $L$. (V.) guyanensis (Figure 1). This was confirmed by nucleotide sequencing of the $1 \mathrm{~kb}$ fragment encompassing ITS1, 5.8S rDNA, and ITS2. The sequence obtained (Genbank number AJ000299.1) showed 99\% identity with L. (V.) guyanensis (MHOM/BR/75/M4147).

3.3. Behavior of the Isolates in In Vitro Culture. Replication rates of the four isolates were similar in complete Grace's medium at $26^{\circ} \mathrm{C}$ during 13 days. The growth curves exhibited typical logarithmic and stationary phases. The parasites formed large clumps at the stationary phase (data not shown). The maximum number of parasites occurred within 4 to 6 days, ranging from around $5 \times 10^{7}$ to $1 \times 10^{8} / \mathrm{mL}$ (Figure 2). After 10 days of culture, parasites of all isolates began to die.

3.4. Course of Infection in Mice. In order to compare the outcome of infection caused by all isolates, stationary-growthphase promastigotes (the 6th day of culture) were inoculated into C57BL/6 WT and BALB/c mouse footpads. Infection was successfully established for all $L$. (V.) braziliensis isolates in $\mathrm{C} 57 \mathrm{BL} / 6 \mathrm{WT}$ and $\mathrm{BALB} / \mathrm{c}$ mice and the lesions increased to a size of approximately 1.0-1.5 mm (Figures 3(a), 3(b), and $3(\mathrm{c})$ ). The infection with the $L$. (V.) guyanensis PLR6 isolate caused a lesion more severe in BALB/c mice than in C57BL/6 $(P<0.05)$, which completely controlled the infection by 11 weeks (Figure 3(d)).

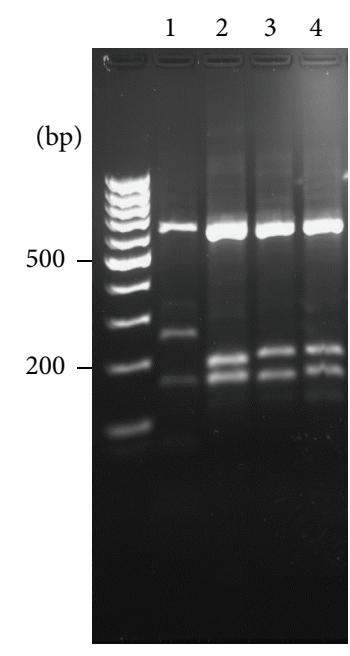

FIgURE 1: Identification of Leishmania PLR6 isolate by ITS1 and 2 amplifications from genomic DNA. The PCR amplified products of approximately $1 \mathrm{~kb}$ were digested with Hae III and restriction fragment analysis was evaluated in an ethidium bromide stained 2\% agarose gel. 1: L. (L.) amazonensis, 2: L. (V.) braziliensis, 3: L. (V.) guyanensis, and 4: PLR6 isolate.

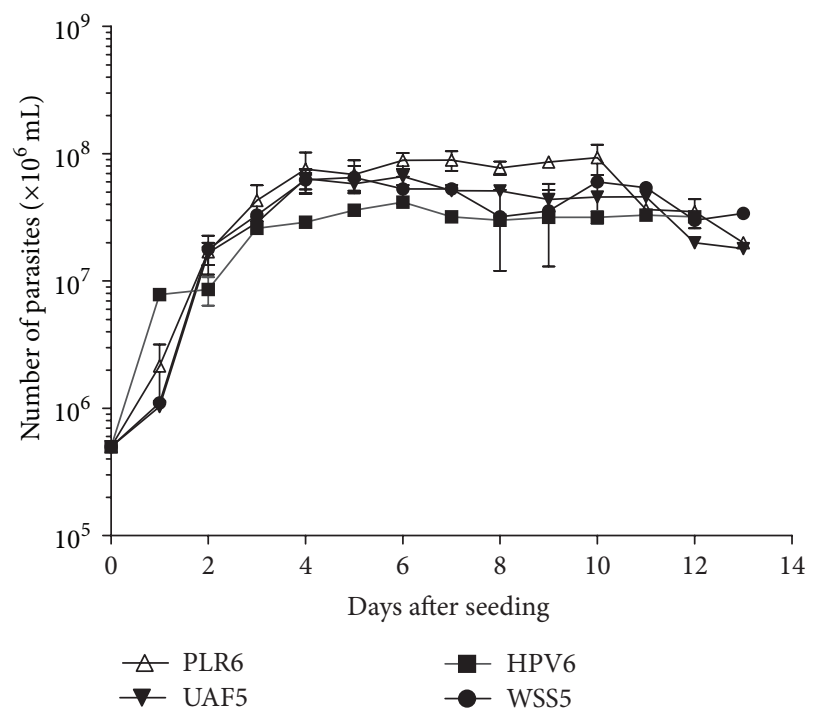

FIgURE 2: In vitro growth curves of Leishmania (V.) braziliensis (HPV6, UAF5, and WSS5) and Leishmania (V.) guyanensis (PLR6) in complete Grace's medium. Parasites were seeded in $5 \times 10^{6} / \mathrm{mL}$ and cultured during 13 days, at $26^{\circ} \mathrm{C}$ in BOD. The data represent mean \pm SEM of two-to-three independent experiments performed in triplicate.

In the absence of IFN $\gamma$ (IFN $\gamma$ KO C57BL/6), progressive lesions developed rapidly, except for the L. (V.) braziliensis WSS5 isolate (Figure 4(a)). Both L. (V.) braziliensis and L. (V.) guyanensis caused ulcerated lesions in IFN $\gamma$ KO C57BL/6 (Figure 4(b)). In IFN $\gamma \mathrm{KO}$ C57BL/6 mice inoculated with L. (V.) guyanensis PLR6 isolate, lesions developed faster 


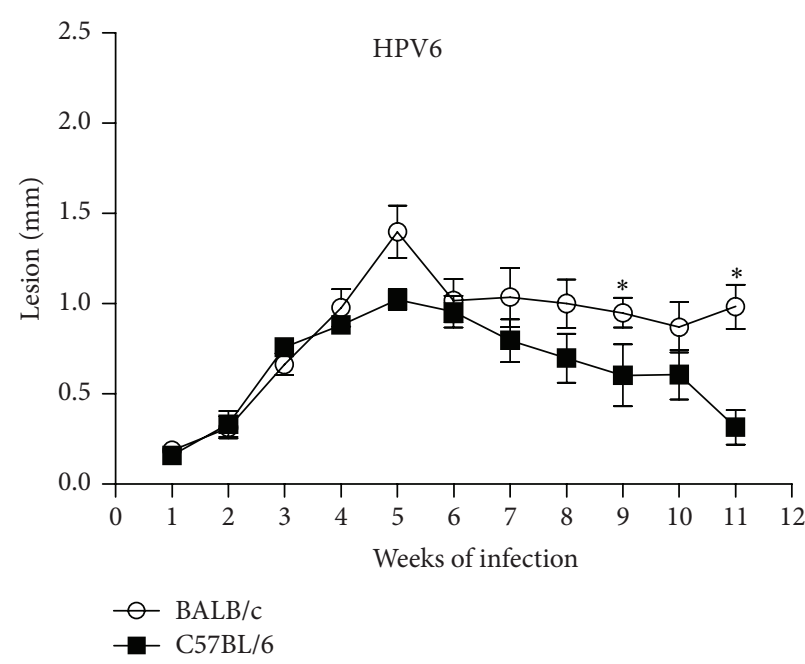

(a)

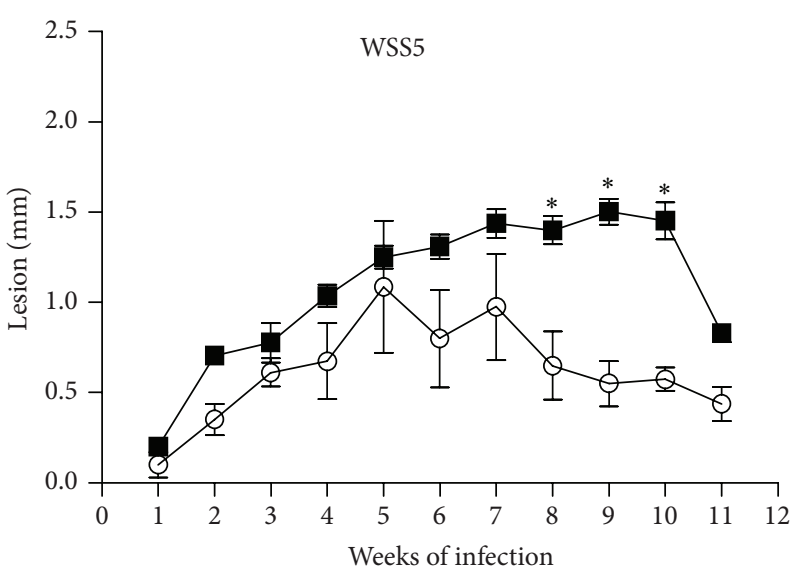

(c)

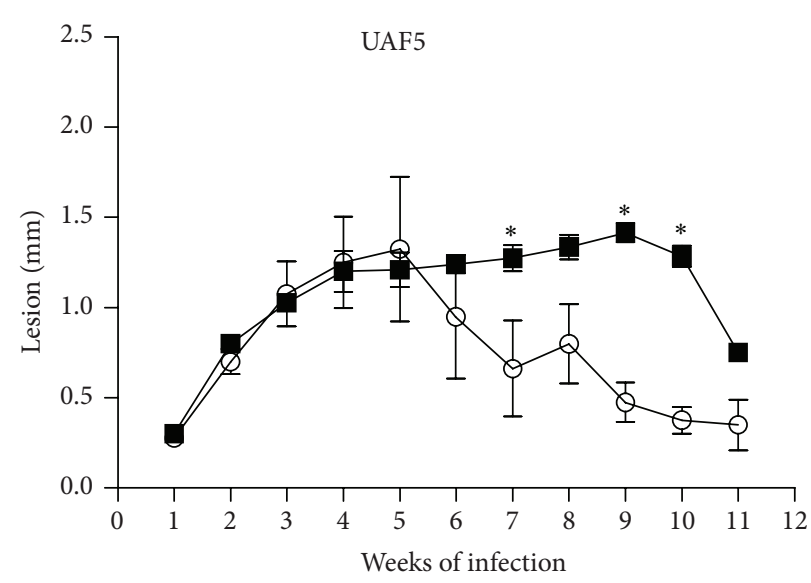

(b)

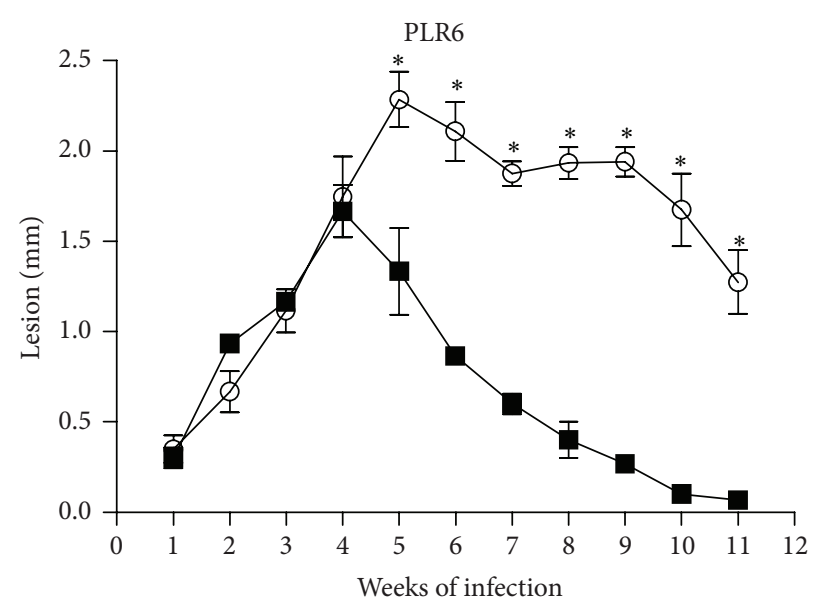

(d)

FIgURE 3: Time course of lesion development in C57Bl/6 WT ( $\bullet$ ) and BALB/c (O) mice infected with Leishmania (V.) braziliensis (HPV6, UAF5, and WSS5) or Leishmania (V.) guyanensis (PLR6). Mice were infected with promastigotes in stationary phase of growth $\left(5 \times 10^{6}\right.$ parasites) into hind footpads. The lesion size was expressed in mm (infected minus control contralateral paw thickness). Data represent mean \pm SEM of results from two or three independent experiments (4-14 animals): HPV6 (a), UAF5 (b), WSS5 (c), and PLR6 (d); ${ }^{*} P<0.05$.

than in mice of the same strain inoculated with $L .(V$. braziliensis (Figure 4(a)) and dissemination of parasites to the contralateral paw (increased thickness) was apparent on the 6th week after infection when the infected footpad began to ulcerate (data not shown).

3.5. Histopathological Analysis. Sections of the footpads obtained on the 1lth week after infection with $L$. (V.) braziliensis WSS5 or L. (V.) guyanensis PLR6 were examined (Figures 5 and 6). On histological examination, the lesions in C57BL/6 footpads infected with either Leishmania isolate were characteristic of the late phase of tissue repair, with hypertrophic scar formation and marked fibrosis in the dermis with few mononuclear inflammatory cells; the epidermis was intact with hyperplasia of epidermal cells (Figures 5(a) and 5(b)). No parasites could be seen at higher magnification (1000x, data not shown).
In comparison, $\mathrm{BALB} / \mathrm{c}$ mice infected with $L$. (V.) braziliensis also presented intact epidermis and superficial dermis but, in the deep dermis, a mononuclear inflammatory infiltrate rich in vacuolated macrophages was located close to and infiltrating the muscle bundles (Figure 5(c)); most macrophages were parasitized with $L$. $(V$.) braziliensis WSS5 (Figure 5(e)). On the other hand, in mice inoculated with L. (V.) guyanensis PLR6, hypertrophic scar and accentuated fibrosis were seen in the dermis and a mononuclear inflammatory infiltrate (Figure 5(d)) with vacuolated macrophages free of intact parasites was observed in the deep dermis (Figure 5(f)).

A marked difference in the histology was seen in IFN $\gamma$ $\mathrm{KO}$ C57BL/6 on the 6th week after inoculation with the same isolates (Figure 6). These mice, inoculated with the L. (V.) braziliensis WSS5 isolate, did not have epidermal ulceration of the paw and from the plantar to dorsal side of 


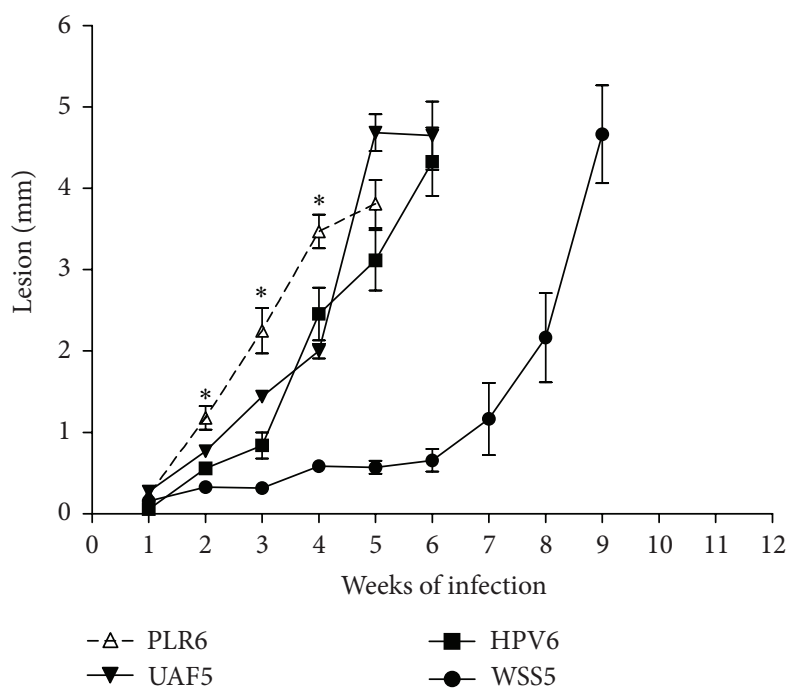

(a)

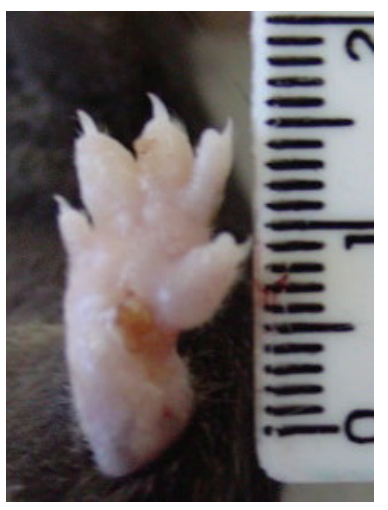

PLR6

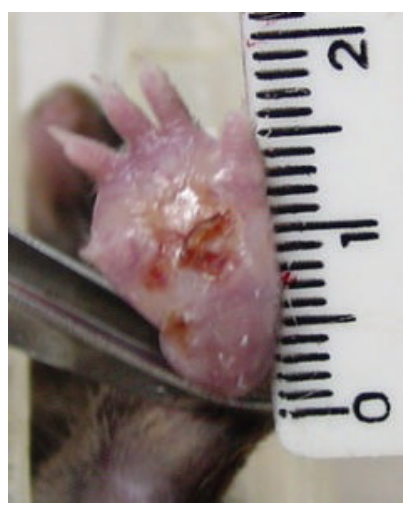

UAF5

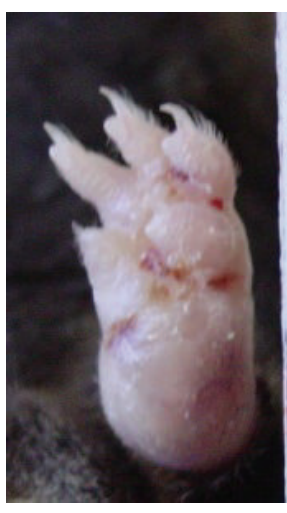

HPV6

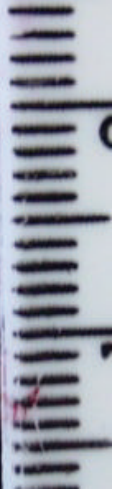

(b)

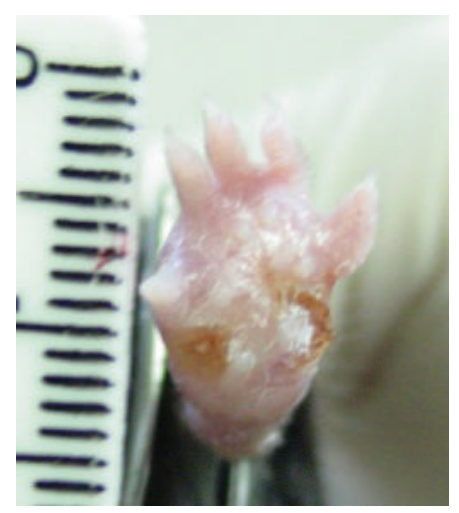

WSS5

Figure 4: Time course of lesion development in IFN $\gamma$-deficient C57BL/6 mice infected with L. (V.) braziliensis (HPV6, UAF5, and WSS5) or L. (V.) guyanensis (PLR6). Lesion size was expressed in $\mathrm{mm}$ (infected minus control contralateral paw thickness). Data represent mean \pm SEM (3-10 animals, (a)), ${ }^{*} P<0.05$. In (b), lesions caused by L. (V.) braziliensis (HPV6, UAF5, and WSS5) or L. (V.) guyanensis (PLR6)

the paw there was an infiltration of mononuclear cells with many parasite-laden macrophages (Figures 6(a) and 6(c)). In contrast, the footpads of mice inoculated with the $L$. (V.) guyanensis PLR6 isolate, as also the other L. (V.) braziliensis isolates, presented a visible ulceration in the plantar surface of the footpad; the inflammatory infiltrate was predominantly mononuclear with areas of necrosis and fibrin deposition near the base of the ulcer (Figures 6(b) and 6(d)); large numbers of parasite-laden macrophages were scattered in the whole dermis (Figure 6(d)).

\section{Discussion}

This report characterizes the Leishmania (Viannia) species isolated from skin biopsies of four patients assisted at the Tropical Diseases Hospital (Anuar Auad, Goiânia, Goiás), with a diagnosis of localized cutaneous leishmaniasis. In our previous studies, three of these isolates were identified as $L$.
(V.) braziliensis (data not shown and [29]) and one remained unidentified. Here, characterization of the ribosomal ITS allowed identification of the latter isolate as L. (V.) guyanensis. It is important to stress here the difficulties in correctly identifying this isolate as $L$. (V.) guyanensis. To achieve this characterization, we have used three strategies: small subunit ribosomal RNA (SSU rDNA) was sequenced [24]; sets of primers for G6PD were used in PCR assays to discriminate L. $(V$.$) braziliensis from other organisms of the Viannia$ subgenus [25]; and ITS was amplified and cloned and the nucleotide sequence of three independent positive clones was phylogenetically analyzed [28]. It is crucial to identify the Leishmania species in order to define which parasites are circulating in a geographic area, to establish the transmission cycles of ATL and to implement the best possible treatment. These points, especially the last one, together with our results, indicate the need of more suitable molecular techniques to define the Leishmania species in the diagnosis of ATL. 


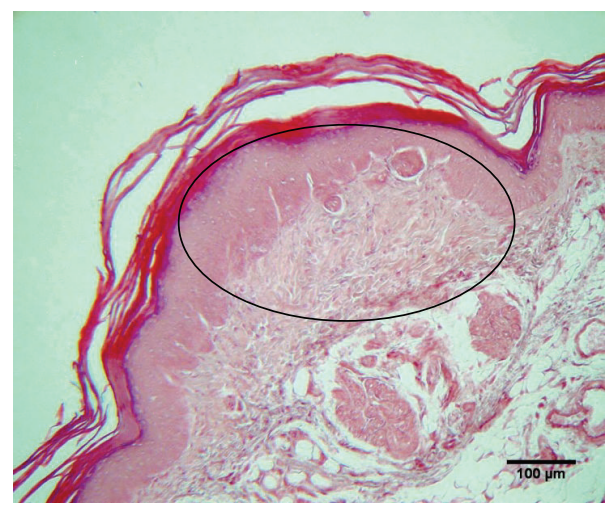

(a)

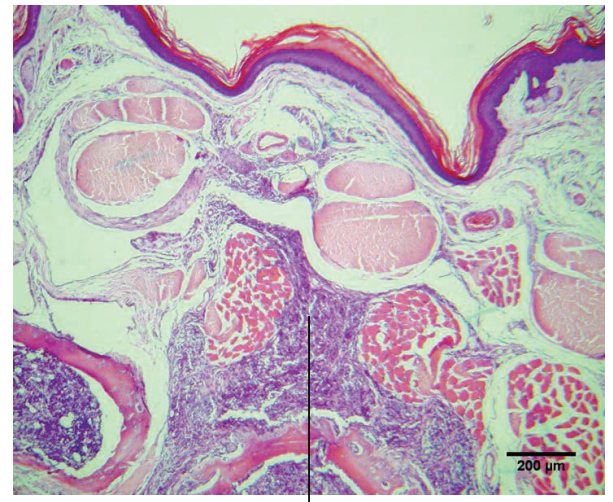

(c)

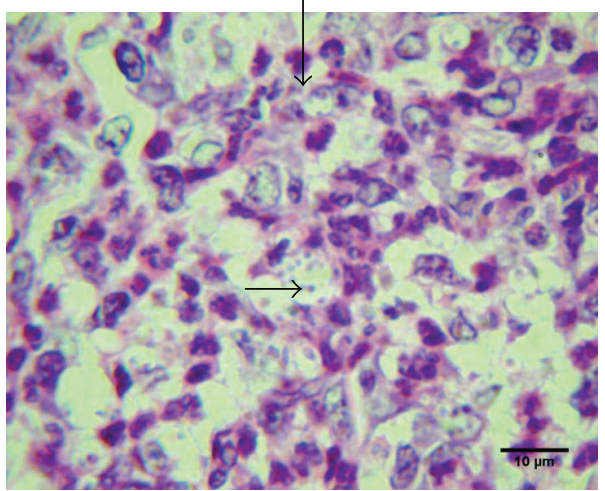

(e)

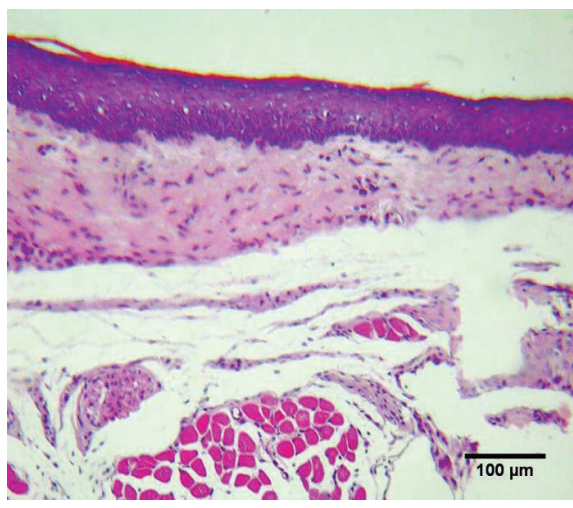

(b)

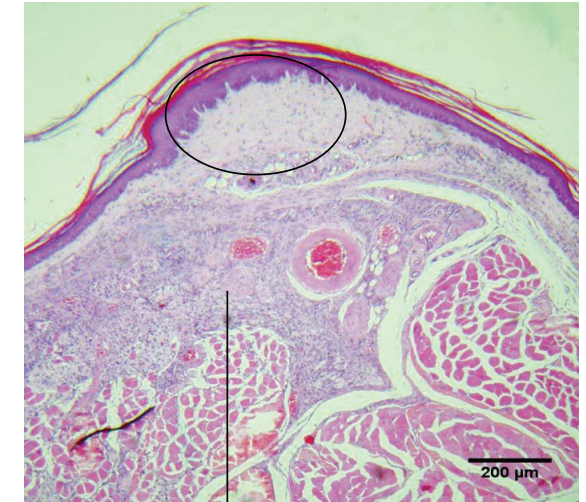

(d)

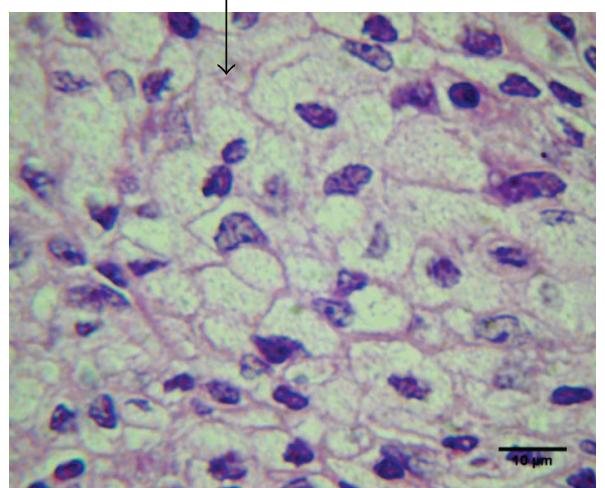

(f)

FIGURE 5: Photomicrographs of nonulcerated lesions obtained from wild-type C57BL/6 and BALB/c mice infected with L. (V.) braziliensis WSS5 or L. (V.) guyanensis PLR6. Mice were inoculated with $5 \times 10^{6}$ parasites at stationary phase of growth, and 11 weeks after infection the histopathology of footpad lesions was evaluated after H\&E staining. (a) C57BL/6 WT mouse infected with L. (V.) braziliensis WSS5, (b) C57BL/6 WT mouse infected with L. (V.) guyanensis PLR6, (c) BALB/c mouse infected with L. (V.) braziliensis WSS5 showing inflammatory infiltration in deep dermis, (d) BALB/c mouse infected with L. (V.) guyanensis PLR6 showing inflammatory infiltrate in deep dermis, (e) $\mathrm{BALB} / \mathrm{c}$ mouse infected with $L$. (V.) braziliensis WSS5 (horizontal black arrow indicates the parasite; vertical black arrow indicates the infiltrate of deep dermis in (c) that contains macrophages and parasites), and (f) BALB/c mouse infected with L. (V.) guyanensis PLR6 (vertical black arrow indicates the mononuclear cell infiltrate in deep dermis in (d) that contains vacuolated macrophages without intact parasites). Areas of hypertrophic scar formation are indicated by the circles in (a) and (d).

In this study, all ATL patients resided in Goiás, but the presumed geographic areas of patient infections for the three L. (V.) braziliensis isolates obtained were Goiás and Tocantins states. The patient infected with $L$. (V.) guyanensis reported having travelled to a forest zone in the boundary of the states Pará (Northern region) and Maranhão (Northeastern region) two months prior to the appearance of lesions. It is known that L. (V.) braziliensis is the parasite largely responsible for ATL in all five Brazilian regions, including Central Western, whereas L. (V.) guyanensis is prevalent only 


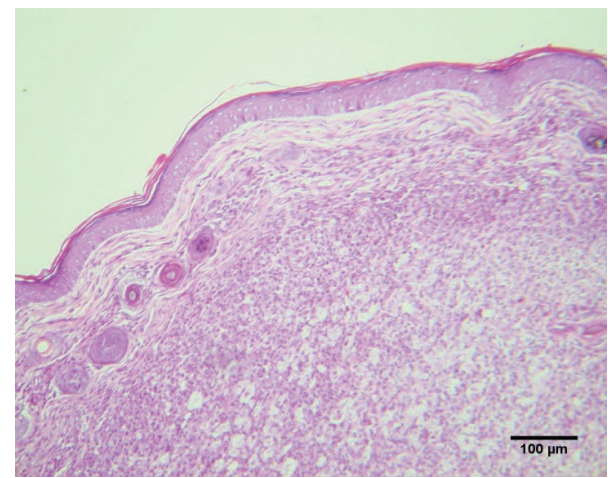

(a)

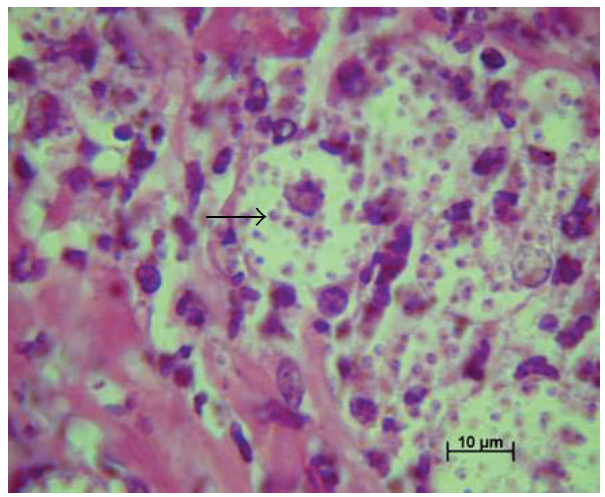

(c)

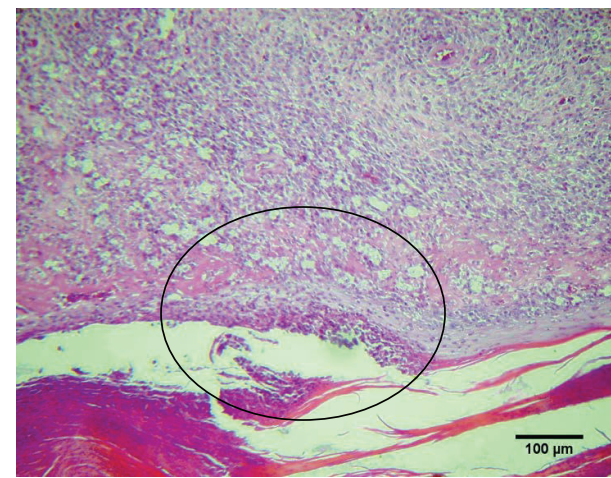

(b)

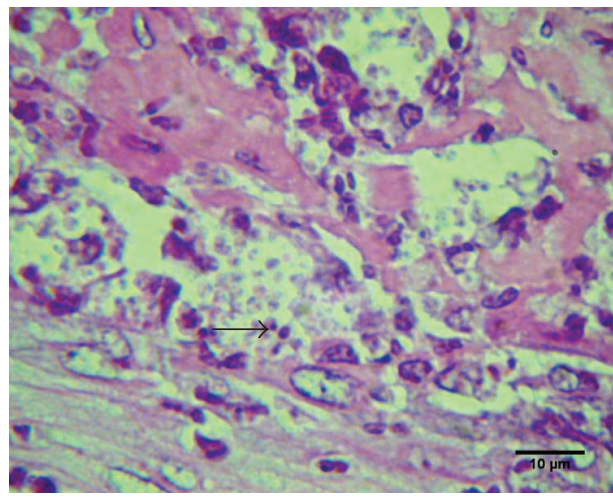

(d)

Figure 6: Photomicrographs of lesions caused by L. (V.) braziliensis WSS5 and L. (V.) guyanensis PLR6 in IFN $\gamma$-deficient C57BL/6 mice. Mice were inoculated with $5 \times 10^{6}$ parasites in stationary phase of growth, and six weeks after infection the histopathology of footpad lesions was evaluated after H\&E staining. (a) Nonulcerated lesion in mouse infected with L. (V.) braziliensis WSS5 isolate, (b) ulcerated lesion in mouse infected with L. (V.) guyanensis PLR6 (the circle shows part of the ulceration that contains mononuclear cells and parasites showed in (d)), (c) mononuclear cell infiltrate with presence of parasites of $L$. (V.) braziliensis WSS5 (black arrow), and (d) mononuclear cells infiltrate with presence of parasites of L. (V.) guyanensis PLR6 (black arrow).

in the Northern region of Brazil, and there are no reports about autochthonous cases of ATL caused by this species in Goiás state or another Brazilian regions $[7,8]$. Thus, our findings confirm the fact that there is a high probability of $L$. (V.) guyanensis being introduced in Goiás state due to the migratory behavior of patients infected with these parasites from the Northern to Central Western region. This possibility is reinforced by the fact that the Tropical Disease Hospital/Anuar Auad assists several patients from the states of the Northern region (around 25\% of the assisted patients, personal communication), pointing out the need of parasite species identification in ATL patients.

The distribution of Leishmania spp. is dependent on vectors and reservoir hosts present in a geographic area. Thus, in Goiás, there are 47 different species of phlebotomine sand flies [14], with a predominance of L. intermedia and $L$. whitmani $[8,13,14]$ which are vectors of $L$. $(V$.) braziliensis in Goiás, Tocantins, Pará, and Maranhão states. For L. (V.) guyanensis, L. umbratilis is the main vector in the Brazilian Northern region; it has not been reported in Goiás $[8,13,14]$.
However, L. umbratilis is also $L$. (V.) braziliensis vector in Mato Grosso (Central Western region); and L. whitmani, which is associated with a great variety of vegetation, including Amazonian forest, Cerrado (savanna, predominant in Goiás), and Caatinga (Northeastern savanna), also transmits L. (V.) guyanensis. Moreover, L. flaviscutellata, present in Goiás, was found to transmit L. (V.) guyanensis. Besides, anteaters and opossums, considered as reservoir of $L$. (V.) guyanensis, are present in Goiás [1, 8, 14, 30-34].

Our findings prompted us to closely evaluate $L$. (V.) guyanensis which has so far been poorly investigated in Brazil. The clinical findings were similar between patients infected with $L$. (V.) braziliensis and with $L$. (V.) guyanensis. The patient infected with $L$. (V.) guyanensis presented three ulcerated lesions and received the treatment but did not return for a follow-up examination. The similarity between clinical manifestations in LCL caused by $L$. (V.) braziliensis and $L$. (V.) guyanensis has been reported, but the response to antimonial treatment can be different $[15,17]$. The isolate L. (V.) guyanensis PLR6 has not been tested for antimonial 
susceptibility, but the other isolates L. (V.) braziliensis HPV6, UAF5, and WSS5 were uniformly susceptible in vitro to meglumine antimoniate and amphotericin B [22].

Corroborating the difficulties in identifying the Leishmania species relying on the clinical findings, our results did not show any difference in the monophasic-culture replication rates among the different isolates. In these cultures, Leishmania species were morphologically similar, and the in vitro growth profiles were similar to those previously described for L. (V.) braziliensis [34].

Our group has previously confirmed that the isolate $L$. (V.) braziliensis HPV6 is able to infect C57BL/6 mice and the J774 murine macrophage cell line [33]. In the present study, we confirmed the infection capacity of this isolate in $\mathrm{C} 57 \mathrm{BL} / 6$ and $\mathrm{BALB} / \mathrm{c}$ mice. All four isolates infected C57BL/6 and $\mathrm{BALB} / \mathrm{c}$ mice. In contrast to $\mathrm{C} 57 \mathrm{BL} / 6 \mathrm{WT}$ mice infected with $L$. (V.) braziliensis isolates, those infected with $L$. (V.) guyanensis PLR6 showed fast regression of the lesion, which almost disappeared after 11 weeks. BALB/c mice also showed nonulcerative skin swelling when infected with all isolates. However, in the deep dermis of L. (V.) guyanensis PLR6infected mice, no parasites were detected inside macrophages whereas in L. (V.) braziliensis WSS5-infected footpads we observed a large number of parasites. The size of lesions caused by (L. (V.) braziliensis) HPV6, UAF5, and WSS5 was similar to those described by Pereira et al. [35] but larger than the size found in murine models of infection with this species [36-38]. de Moura et al. [39] reported that inoculation of L. (V.) braziliensis into the ear dermis of BALB/c mice leads to the development of an ulcerated lesion. The discrepancies with our results could be related to the site of inoculation or the virulence of the parasite strain. Considering the size and time course of the infection caused by $L$. (V.) guyanensis PLR6, our results were similar to those obtained by SousaFranco et al. [40], and like these authors we did not find parasites inside macrophages after 11 weeks of infection.

In this study, high susceptibility of IFN $\gamma \mathrm{KO}$ C57BL/6 mice to all four isolates confirms a close association between resistance and production of Th1 cytokines (IFN $\gamma$ ) during the course of L. (Viannia) spp. infection as has been described by de Souza-Neto et al. [41] in one L. (V.) braziliensis mouse model. The infection of IFN $\gamma$ KO C57BL/6 showed macroscopical and microscopical differences between infected footpads of mice inoculated either with $L$. (V.) braziliensis or L. (V.) guyanensis. The development of the lesion caused by L. (V.) guyanensis PLR6 was faster than those caused by $L$. (V.) braziliensis isolates and PLR6 caused cutaneous metastatic lesions that could be observed in the contralateral footpad. The histopathology analysis showed parasites in the ulcerative area in lesions from the 5 th week after infection. Secondary cutaneous metastatic lesions induced by $L$. (V.) guyanensis have also been reported in hamsters [42]. On the other hand, on the 5th week of infection, the whole extension of $L$. (V.) braziliensis WSS5-infected footpad consisted of an intense inflammatory infiltration full of parasites, without signs of ulceration; however, after nine weeks of infection, this parasite induced the same ulceration as the other $L$. (V.) braziliensis isolates. As C57BL/6 WT mice presented better control of the L. (V.) guyanensis infection and the development of the lesion caused by this species was faster than that caused by L. (V.) braziliensis in IFN $\gamma$ KO C57BL/6 mice, it can be suggested that $L$. (V.) guyanensis can present higher susceptibility to leishmanicidal mechanisms induced by IFN $\gamma$ than L. (V.) braziliensis. The highest susceptibility of IFN $\gamma$ KO C57BL/6 to L. (Viannia) spp. led us to use this mouse strain for the process of parasite isolation from lesions of ATL patients [21, 43].

ATL has been considered as a social and economic problem of the poor population which has resulted largely from an intense migratory movement into rural areas and the forested hillsides that are close to the outskirts of the urban centers. However, due to the intense international travel and the large contingents of displaced and migratory populations, Tegumentary Leishmaniasis has to be considered as a diagnosis of nonhealing indolent ulcers also in nonendemic areas. Moreover, infection by L. (V.) guyanensis has been diagnosed in Europe in a soldier who denied travelling to endemic areas or having blood transfusions, raising some uncommon possibilities of contagion [44].

Nowadays, migration among Brazilian regions has largely increased, both inside forested areas and in urban areas. The finding of infection with $L$. (V.) guyanensis in a patient residing in the state of Goiás, where species other than $L$. (V.) braziliensis and $L$. (L.) amazonensis had not been previously described [7, 8, 45], improves the knowledge about ATL spreading pattern and reinforces the need for surveillance, control, and prevention of new ATL foci in Brazil. The difficulties to differentiate L. (V.) guyanensis from L. (V.) braziliensis at several levels, such as molecular, morphological, and clinical ones, draw attention to the possible underestimated prevalence of $L$. (V.) guyanensis in different Brazilian regions. Besides this contribution, our results also increased the knowledge on L. (V.) guyanensis infectivity in murine infection models, suggesting that IFN $\gamma$ can be more relevant for controlling L. (V.) guyanensis than L. (V.) braziliensis.

\section{Conclusions}

We have isolated and characterized three clinical field isolates of Leishmania spp., from patients probably infected in Goiás, Tocantins, and Pará states, Brazil, as L. (Viannia) braziliensis and one as L. (V.) guyanensis. The latter species had not yet been described in Goiás. Infection of mouse strains $\mathrm{BALB} / \mathrm{c}, \mathrm{C} 57 \mathrm{BL} / 6$ wild-type, and C57BL/ 6 lacking gammainterferon (IFN $\gamma$ KO C57BL/6) showed differences in lesion development among the Leishmania strains. In addition, better infection control of $L$. (V.) guyanensis than $L$. (V.) braziliensis was observed in mice in the presence of IFN $\gamma$ but not in the absence of this cytokine. Molecular identification of $L$. (V.) guyanensis in a patient resident in Goiás stresses the importance of correct species identification and suggests that the presence of this species is possibly underestimated in several areas of Brazil.

\section{Conflict of Interests}

The authors declare that there is no conflict of interests regarding the publication of this paper. 


\section{Acknowledgments}

This work was supported by SECTEC/GO (68.0067/2004-3, Proc. Ind: 35.0185/2005-0 NV), CNPq, and CAPES (PROCAD NF-179). Dr. Gloria Maria Collet de Araújo Lima was a DCR fellow (Brazilian program for regional development) supported by CNPq. Silvia Reni B. Uliana is the recipient of a senior researcher scholarship from CNPq. Adriano Cappellazzo Coelho is supported by FAPESP (2012/14629-5). The authors are in debt to Dr. Lucile Winter-Floeter from the University of São Paulo for helping them with PCR techniques.

\section{References}

[1] R. W. Ashford, "The leishmaniases as emerging and reemerging zoonoses," International Journal for Parasitology, vol. 30, no. 1213, pp. 1269-1281, 2000.

[2] R. Reithinger, J.-C. Dujardin, H. Louzir, C. Pirmez, B. Alexander, and S. Brooker, "Cutaneous leishmaniasis," Lancet Infectious Diseases, vol. 7, no. 9, pp. 581-596, 2007.

[3] J. Alvar, I. D. Vélez, C. Bern et al., "Leishmaniasis worldwide and global estimates of its incidence," PLoS ONE, vol. 7, no. 5, Article ID e35671, 2012.

[4] Ministério da Saúde, Manual de Vigilância da Leishmaniose Tegumentar Americana, 2007, http://www.crmv-mt.org.br/images/bt-arise/Artigos/manual_lta_2ed.pdf.

[5] SINAN/SVS/MS, "Coeficiente de detecção de casos de Leishmaniose Tegumentar Americana por 100.000 habitantes. Brasil, Grandes Regiões e Unidades Federadas. 1990 a 2010," 2014, http://portal.saude.gov.br/portal/arquivos/pdf/lta_deteccao_08_ 09_11.pdf.

[6] SINAN/SVS/MS, Casos de Leishmaniose Tegumentar Americana. Brasil, Grandes Regiões e Unidades Federadas. 1990 a 2013, 2013, http://portalsaude.saude.gov.br/images/pdf/2014/setembro/09/LT-Casos.pdf.

[7] G. Grimaldi Jr., J. R. David, and D. McMahon-Pratt, "Identification and distribution of New World Leishmania species characterized by serodeme analysis using monoclonal antibodies," The American Journal of Tropical Medicine and Hygiene, vol. 36, no. 2, pp. 270-287, 1987.

[8] Ministério da Saúde, Manual de Vigilância da Leishmaniose Tegumentar Americana, Ministério da Saúde, Brasília, Brazil, 2010, http://bvsms.saude.gov.br/bvs/publicacoes/manual_vigilancia_leishmaniose_tegumentar_americana.pdf.

[9] E. Cupolillo, H. Momen, and G. Grimaldi Jr., "Genetic diversity in natural populations of new world Leishmania," Memorias do Instituto Oswaldo Cruz, vol. 93, no. 5, pp. 663-668, 1998.

[10] E. Cupolillo, L. R. Brahim, C. B. Toaldo et al., "Genetic polymorphism and molecular epidemiology of Leishmania (Viannia) braziliensis from different hosts and geographic areas in Brazil," Journal of Clinical Microbiology, vol. 41, no. 7, pp. 3126-3132, 2003.

[11] A. C. R. Azevedo, N. A. Souza, C. R. V. Meneses et al., "Ecology of sand flies (Diptera: Psychodidae: Phlebotominae) in the north of the State of Mato Grosso, Brazil," Memorias do Instituto Oswaldo Cruz, vol. 97, no. 4, pp. 459-464, 2002.

[12] N. A. Missawa, G. B. M. L. Maciel, and H. Rodrigues, "Geographical distribution of Lutzomyia (Nyssomyia) whitmani (Antunes \& Coutinho, 1939) in the State of Mato Grosso," Revista da Sociedade Brasileira de Medicina Tropical, vol. 41, no. 4, pp. 369-373, 2008.
[13] F. Martins, I. G. Da Silva, W. A. Bezerra et al., "Diversidade e frequencia da fauna flebotomínea (Diptera: Psychodidae) em áreas com transmissão de leishmaniose, no estado de Goiás," Revista de Patologia Tropical, vol. 31, no. 2, pp. 221-224, 2002.

[14] P. S. de Almeida, A. J. de Andrade, A. Sciamarelli et al., "Geographic distribution of phlebotomine sandfly species (Diptera: Psychodidae) in Central-West Brazil," Memórias do Instituto Oswaldo Cruz, vol. 110, no. 4, pp. 551-559, 2015.

[15] G. A. S. Romero, M. V. Guerra, M. G. Paes, and V. O. Macêdo, "Comparison of cutaneous leishmaniasis due to Leishmania (Viannia) braziliensis and L. (V.) guyanensis in Brazil: therapeutic response to meglumine antimoniate," The American Journal of Tropical Medicine and Hygiene, vol. 65, no. 5, pp. 456-465, 2001.

[16] P. Couppié, E. Clyti, D. Sainte-Marie, J. P. Dedet, B. Carme, and R. Pradinaud, "Disseminated cutaneous leishmaniasis due to Leishmania guyanensis: case of a patient with 425 lesions," American Journal of Tropical Medicine and Hygiene, vol. 71, no. 5, pp. 558-560, 2004.

[17] J. Arevalo, L. Ramirez, V. Adaui et al., "Influence of Leishmania (Viannia) species on the response to antimonial treatment in patients with American tegumentary leishmaniasis," Journal of Infectious Diseases, vol. 195, no. 12, pp. 1846-1851, 2007.

[18] J. A. D. O. Guerra, S. R. Prestes, H. Silveira et al., "Mucosal Leishmaniasis caused by Leishmania (Viannia) braziliensis and Leishmania (Viannia) guyanensis in the Brazilian Amazon," PLoS Neglected Tropical Diseases, vol. 5, no. 3, article e980, 2011.

[19] A. Schriefer, A. L. F. Schriefer, A. Góes-Neto et al., "Multiclonal Leishmania braziliensis population structure and its clinical implication in a region of endemicity for American tegumentary leishmaniasis," Infection and Immunity, vol. 72, no. 1, pp. 508-514, 2004

[20] M. C. Boité, I. L. Mauricio, M. A. Miles, and E. Cupolillo, "New insights on taxonomy, phylogeny and population genetics of Leishmania (Viannia) parasites based on multilocus sequence analysis," PLoS Neglected Tropical Diseases, vol. 6, no. 11, Article ID e1888, 2012.

[21] M. A. P. de Oliveira, A. D. S. Pires, R. P. de Bastos et al., "Leishmania spp. parasite isolation through inoculation of patient biopsy macerates in interferon gamma knockout mice," Revista do Instituto de Medicina Tropical de São Paulo, vol. 52, no. 2, pp. 83-88, 2010.

[22] R. C. Zauli-Nascimento, D. C. Miguel, J. K. U. YokoyamaYasunaka et al., "In vitro sensitivity of Leishmania (Viannia) braziliensis and Leishmania (Leishmania) amazonensis Brazilian isolates to meglumine antimoniate and amphotericin B," Tropical Medicine and International Health, vol. 15, no. 1, pp. 6876, 2010.

[23] E. S. M. Mouriz Savani, V. L. Brandão Nunes, E. A. Bianchi Galati et al., "Ocurrence of co-infection by Leishmania (Leishmania) chagasi and Trypanosoma (Trypanozoon) evansi in a dog in the state of Mato Grosso do Sul, Brazil," Memorias do Instituto Oswaldo Cruz, vol. 100, no. 7, pp. 739-741, 2005.

[24] S. R. B. Uliana, K. Nelson, S. M. Beverley, E. P. Camargo, and L. M. Floeter-Winter, "Discrimination amongst Leishmania by polymerase chain reaction and hybridization with small subunit ribosomal DNA derived oligonucleotides," Journal of Eukaryotic Microbiology, vol. 41, no. 4, pp. 324-330, 1994.

[25] T. M. Castilho, J. J. Shaw, and L. M. Floeter-Winter, "New PCR assay using glucose-6-phosphate dehydrogenase for identification of Leishmania species," Journal of Clinical Microbiology, vol. 41, no. 2, pp. 540-546, 2003. 
[26] E. Cupolillo, G. Grimaldi Jr., H. Momen, and S. M. Beverley, "Intergenic region typing (IRT): a rapid molecular approach to the characterization and evolution of Leishmania," Molecular and Biochemical Parasitology, vol. 73, no. 1-2, pp. 145-155, 1995.

[27] G. Schönian, A. Nasereddin, N. Dinse et al., "PCR diagnosis and characterization of Leishmania in local and imported clinical samples," Diagnostic Microbiology and Infectious Disease, vol. 47, no. 1, pp. 349-358, 2003.

[28] A. Stamatakis, "RAxML version 8: a tool for phylogenetic analysis and post-analysis of large phylogenies," Bioinformatics, vol. 30, no. 9, pp. 1312-1313, 2014.

[29] D. P. Depledge, L. M. MacLean, M. R. Hodgkinson et al., "Leishmania-specific surface antigens show sub-genus sequence variation and immune recognition," PLoS Neglected Tropical Diseases, vol. 4, no. 9, article e829, 2010.

[30] S. M. da Costa, M. Cechinel, V. Bandeira, J. C. Zannuncio, R. Lainson, and E. F. Rangel, "Lutzomyia (Nyssomyia) whitmani s.l. (Antunes \& Coutinho, 1939)(Diptera: Psychodidae: Phlebotominae): geographical distribution and the epidemiology of American cutaneous leishmaniasis in Brazil-mini-review," Memorias do Instituto Oswaldo Cruz, vol.102, no. 2, pp. 149-153, 2007.

[31] J. Shaw, "The leishmaniases-survival and expansion in a changing world. A mini-review," Memorias do Instituto Oswaldo Cruz, vol. 102, no. 5, pp. 541-546, 2007.

[32] F. Fouque, P. Gaborit, J. Issaly et al., "Phlebotomine sand flies (Diptera: Psychodidae) associated with changing patterns in the transmission of the human cutaneous leishmaniasis in French Guiana," Memórias do Instituto Oswaldo Cruz, vol. 102, no. 1, pp. 35-40, 2007.

[33] P. M. Leite, R. S. Gomes, A. B. Figueiredo et al., "Ecto-nucleotidase activities of promastigotes from Leishmania (Viannia) braziliensis relates to parasite infectivity and disease clinical outcome," PLoS Neglected Tropical Diseases, vol. 6, no. 10, Article ID e1850, 2012.

[34] I. A. da Silva, C. I. Morato, V. B. L. Quixabeira et al., "In vitro metacyclogenesis of Leishmania (Viannia) braziliensis and Leishmania (Leishmania) amazonensis clinical field isolates, as evaluated by morphology, complement resistance, and infectivity to human macrophages," BioMed Research International, vol. 2015, Article ID 393049, 15 pages, 2015.

[35] C. G. Pereira, A. L. N. Silva, P. de Castilhos et al., "Different isolates from Leishmania braziliensis complex induce distinct histopathological features in a murine model of infection," Veterinary Parasitology, vol. 165, no. 3-4, pp. 231-240, 2009.

[36] T. U. Maioli, E. Takane, R. M. E. Arantes, J. L. R. Fietto, and L. C. C. Afonso, "Immune response induced by New World Leishmania species in C57BL/6 mice," Parasitology Research, vol. 94, no. 3, pp. 207-212, 2004.

[37] C. Indiani de Oliveira, M. J. Teixeira, C. R. Teixeira et al., "Leishmania braziliensis isolates differing at the genome level display distinctive features in BALB/c mice," Microbes and Infection, vol. 6, no. 11, pp. 977-984, 2004.

[38] F. J. S. Rocha, U. Schleicher, J. Mattner, G. Alber, and C. Bogdan, "Cytokines, signaling pathways, and effector molecules required for the control of Leishmania (Viannia) braziliensis in mice," Infection and Immunity, vol. 75, no. 8, pp. 3823-3832, 2007.

[39] T. R. de Moura, F. O. Novais, F. Oliveira et al., "Toward a novel experimental model of infection to study American cutaneous leishmaniasis caused by Leishmania braziliensis," Infection and Immunity, vol. 73, no. 9, pp. 5827-5834, 2005.
[40] J. Sousa-Franco, É. Araújo-Mendes, I. Silva-Jardim et al., "Infection-induced respiratory burst in BALB/c macrophages kills Leishmania guyanensis amastigotes through apoptosis: possible involvement in resistance to cutaneous leishmaniasis," Microbes and Infection, vol. 8, no. 2, pp. 390-400, 2006.

[41] S. M. de Souza-Neto, C. M. Carneiro, L. Q. Vieira, and L. C. C. Afonso, "Leishmania braziliensis: partial control of experimental infection by interleukin-12 p40 deficient mice," Memorias do Instituto Oswaldo Cruz, vol. 99, no. 3, pp. 289-294, 2004.

[42] J. E. Martinez, B. L. Travi, A. Z. Valencia, and N. G. Saravia, "Metastatic capability of Leishmani (Viannia) panamensis and Leishmania (Viannia) guyanensis in golden hamsters," Journal of Parasitology, vol. 77, no. 5, pp. 762-768, 1991.

[43] M. L. Dorta, M. A. P. Oliveira, A. K. A. Fleuri et al., "Improvements in obtaining New World Leishmania sp from mucosal lesions: notes on isolating and stocking parasites," Experimental Parasitology, vol. 132, no. 2, pp. 300-303, 2012.

[44] W. Poeppl, H. Burgmann, H. Auer, G. Mooseder, and J. Walochnik, "Leishmania (Viannia) guyanensis infection, Austria," Emerging Infectious Diseases, vol. 18, no. 9, pp. 1534-1535, 2012.

[45] M. L. Dorta, C. S. Gosch, R. O. Dorta, L. I. A. Pereira, A. J. S. Pereira, and F. Ribeiro-Dias, "American cutaneous leishmaniasis in a rural area of Goiás state, Brazil," Revista do Instituto de Medicina Tropical de São Paulo, vol. 45, supplement 13, p. 136, 2003. 

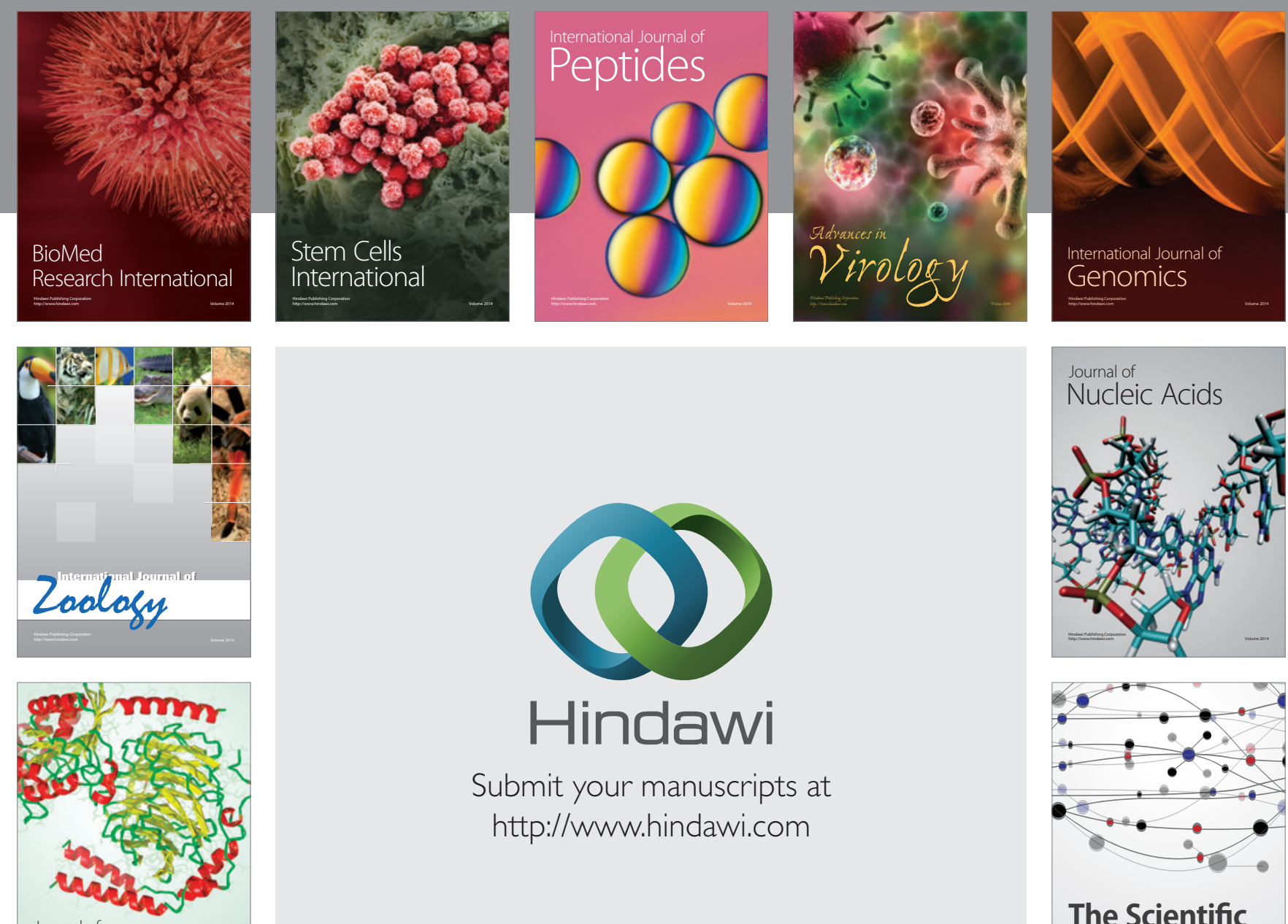

Submit your manuscripts at

http://www.hindawi.com

Journal of
Signal Transduction
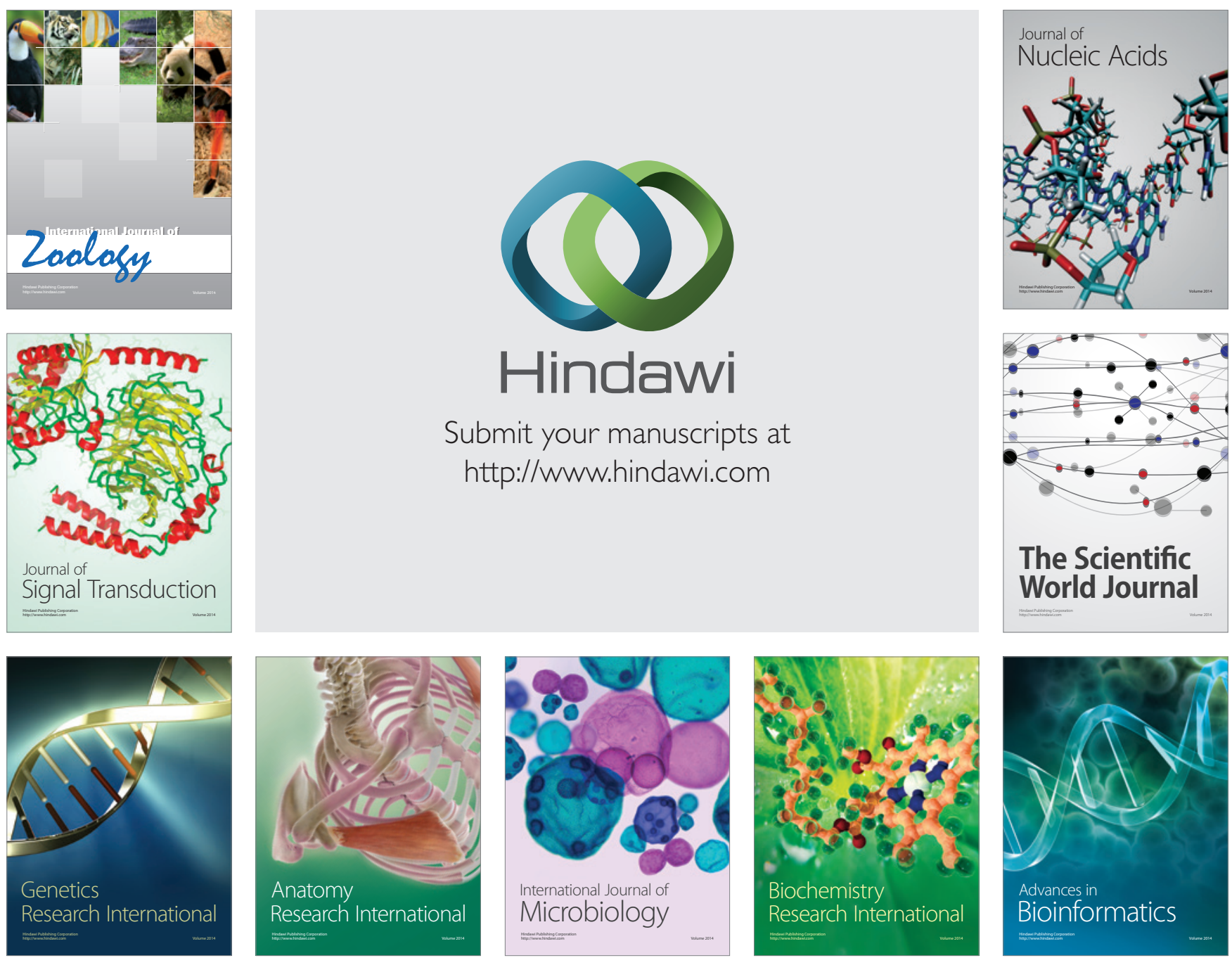

The Scientific World Journal
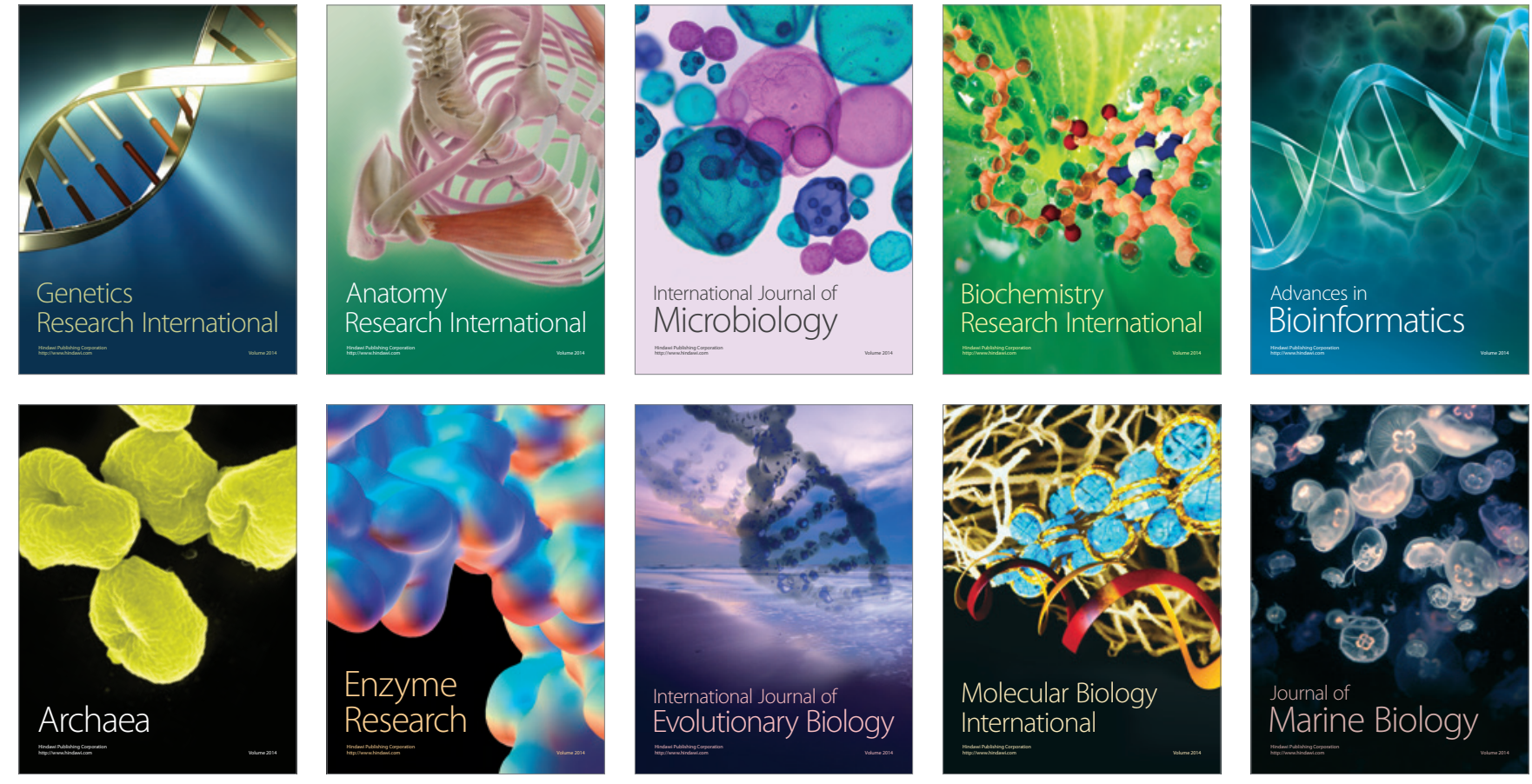